\title{
DIE BOU VAN DIE OPVOEDKUNDE AAN ONS
}

\section{UNIVERSITEIT}

\section{Stelling:}

Die ontwikkeling van die Opvoedkunde aan ons Inrigting het in twee aaneensluitende rigtings gegaan: die een het uit die ander en daarna ewewydig of voorbereidend aan die ander ontwikkel. Die eerste wat ontstaan het, is die rigting van die opleiding van onderwysers, en die ander die rigting van die opleiding vir akademiese grade in die Opvoedkunde (die Baccalaureus, die Magister en die Doctor).

\section{Die opleiding van onderwysers:}

Toe die Teologiese Skool van die Gereformeerde Kerk in Suid-Afrika op 29 November 1869 geopen is met die oog op die opleiding van dié kerk se predikante, het die voorvaders gelyktydig begin met die plan van die professionele en akademiese opleiding van onderwysers, en ook met ,aanvorming" aan jong manne vir geen bepaalde beroep nie, dus vir algemene akademiese geleerdheid. Só is dit bepaal op die Algemene Sinodale Vergadering in Mei 1869. Reeds in 1876 het die Sinode verder besluit, omrede die behoefte en die gunstige ontwikkeling van die Skool, tot die benoeming van twee professore, een teologies deur die Sinode te benoem en die ander literaries deur die Kuratore van die Skool te benoem - en daar was toe reeds sprake van die benoeming van ' $n$ bevoegde onderwyser met die hoofonderwysersrang vir die opleiding van onderwysers (dit het wel nie gebeur nie). In 1877 begin die eerste literariese professor (P. Postma, B.A.) as die professor in die literariese en pedagogiese vakke.

Op die Algemene Sinodale Vergadering van 1879 het die Kuratore van die Skool met blydskap gerapporteer dat drie van die studente met goeie gevolg hul goewernementseksamen as onderwysers afgelê het. Hulle is die eerste onderwysers wat aan ons Inrigting opgelei is - en hul name verdien inderdaad vermelding: mnr. (later ds.) Dirk Postma jr., mnr. (later ds.) Louis Petrus Vorster, en mnr. (later sakeman en politikus) Antonie Charles Auguste van Rooy. In 1881 kon die Kuratore weer rapporteer dat 2 onderwysers en 3 matrikulante in hul eksamens geslaag het. 
Die volgende belangrike ontwikkeling in die opleiding van onderwysers het gekom in 1894, toe op die Algemene Sinodale Vergadering ter sprake gekom het as een van die vier hoofsake op die Sinode die instelling van 'n eie Onderwyserseksamen. $\mathrm{Na}$ bespreking is deur die Sinode 'n skema vir die Onderwyseksamen aanvaar. Die skema het die volgende hoofpunte ingesluit: Die hoofdoel van die eksamen is om te voorsien in die sertifisering van onderwysers aan die skole van die Gereformeerde Kerk. Die vereistes is soos volg: (1) Skoolhoofde moet in besit wees van die Tweede Klas-onderwyserseksamen van die Zuid-Afrikaanse Republiek of van die Oranje-Vrystaat of die Matrikulasie van die Universiteit van die Kaap die Goeie Hoop met 'n bykomende eksamen in die Hollandse Taal, Geskiedenis van Suid-Afrika en 'n oorsig van die Wêreldgeskiedenis, Opvoedkunde (beginsels, skoolinrigting, aanskouing), en Tekene en Sangkunde. (2) Assistente moet in besit wees van die Derde Klas-onderwyserseksamen van die twee Republieke (Z.A.R. of O.V.S.) of van die Kaap-Kolonie met Sangkunde. (3) Vir alle onderwysers moet nog bykom 'n eksamen in Bybelse Geskiedenis (Oue en Nuwe Testament), Bybelse Aardrykskunde, Algemene Kerkgeskiedenis en van die Gereformeerde Kerk in Nederland en Suid-Afrika, en Kategetiek met die oog op Godsdiensonderrig. (4) Onderwysers moet in besit wees van 'n attestasie van die Gereformeerde Kerk. (5) Die Teologiese Skool moet in sy Literariese Departement self die onderwysers oplei, en 'n tydsduur van opleiding aan die Skool moet vasgestel word. Die kommissie ad hoc was die predikante P. Postma, J. Vorster en M. Postma.

Eers weer in 1911 na die Driejarige Oorlog, die naweë van die oorlog en die gevolge van die unifikasie van die vier Suid-Afrikaanse provinsies het die Kuratore ernstige aandag gegee aan die opleiding van onderwysers aan die Teologiese Skool. Die plasing van alle hoër onderwys onder die Uniale Minister van Onderwys het vanself ook die Literariese Departement van die Teologiese Skool drasties geraak. Aan die sg. Universiteitskolleges (Kaapstad, Stellenbosch, Bloemfontein, Pretoria) is kursusse vir die opleiding van onderwysers ingestel en is daar professore in die Opvoedkunde aangestel. Die Kuratore het einde 1911 ernstig oorweeg om ook aan die Teologiese Skool 'n professor in die Opvoedkunde, naas die professore in Lettere en Natuurwetenskappe, aan te stel met die oog op die vakkundige opleiding van onderwysers. So 'n professor kon 
glo nie nou al gevind of aangestel word nie. Na die benoeming van ' $n$ tweede professor in die Teologie aan die Skool in 1914 het die Kuratore die dienste van hul nuwe professor (dr. S. 0 . Los wat 'n grondige studie van die Opvoedkunde gemaak het) tot hul beskikking gehad. Hy het toe aan belangstellende jong manne en diensdoende onderwysers (soos die ondergetekende van 1917 af) onderrig gegee in die Gereformeerde Pedagogiek, hoofsaaklik teoreties en histories van aard.

$\mathrm{Na} 1916$ het die toestand van die Literariese Departement van ons Teologiese Skool uit akademiese en finansiële oogpunt werklik kritiek geword. In daardie jaar het die nuwe HoërOnderwyswetgewing van krag geword. Twee doserende universiteite (Kaapstad en Stellenbosch) het tot stand gekom en 'n derde universiteit met konstituerende kolleges (Suid-Afrika) is ook geskep. Die Universiteit van Suid-Afrika was 'n eksaminerende universiteit; die doseerwerk is verrig deur die sg. Samestellende Universiteitskolleges. Nou was die harde feit daar: die professore en dosente van die Universiteitskollege is erken en aanvaar ook as eksaminatore, maar die van die Literariese Departement van die Potchefstroomse Teologiese Skool nie - met die gevolg dat ons studente volslae eksterne studente geword het. Die ernstige vraag was nou: Kan die Gereformeerde Kerk voortgaan met sy eie Literariese Departement? Dit het die kerk toenemend groter finansiële sorge gebring, en dit het nou ook die akademiese etiket van nie-erkenning as 'n universitêre kollege gekry. Die gevolg was dat die Literariese Departement op besluit van die Sinodes van 1916 en 1918 heeltemal los gemaak is van die Teologiese Skool as sodanig. $\mathrm{Na}$ die afstigting van die Literariese Departement as die Potchefstroomse Universiteitskollege vir Kristelike Hoër Onderwys in April 1919, het die nuwe Kollegeraad 'n baie belangrike besluit geneem - en dit op die inisiatief van sy Rektor, prof. dr. F. Postma.

Hierdie nuwe besluit was van beslissende betekenis in die opleiding van onderwysers aan ons Inrigting. In 1920 begin die nuwe Kollege met die opleiding van studente vir die UnieEersteklas-onderwyserseksamen onder die Unie-Onderwysdepartement. Die Kollegeraad het vir 1920 as deeltydse dosent vir die kursus 0.1 benoem die skrywer self. Die 0. 1-kursus self is vir die eerste maal in 1913-1914 aangebied aan die sg. Kolleges van die Ou Kaapse Universiteit, en die skrywer was self een van die eerste drie studente aan die Bloemfonteinse 
Grey-universiteitskollege vir die nuwe O. 1-eksamen. Die kursus is van 1920 tot 1923 aan ons Inrigting aangebied. Dit het 18 maande geduur; dit was bedoel veral vir aanstaande skoolhoofde; dit was 'n nagraadse (B.A.) kursus; die eksamen het bestaan uit twee dele, 'n voorlopige en ' $n$ finale; 'n onderwysdiploma word uitgereik voorlopig na die 18 maande en finaal na nog drie jaar skoolervaring en die inlewering van 'n tesis oor ' $n$ opvoedkundige vraagstuk. Die kursus self het uit twee dele bestaan: plus minus 2 of meer moderne tale (stelwerk en elokusie); teorie en praktyk van die laerskool-onderwys; bordwerk en tekene; handwerk; sang of snel- en tikskrif; skoolhigiëne en liggaamsoefeninge; 2 of meer tale (stelwerk, elokusie, fonetiek); Geskiedenis van die Opvoedkunde, algemeen en SuidAfrikaans; Wetenskaplike en filosofiese grondslae van die Opvoedkunde (Sielkunde, Logika, Sedeleer); teorie en praktyk van die middelbare-skoolonderwys; handewerk; sang of snelen tikskrif; twee vakke van die middelbare skool. Die eksamen vir deel I kon afgeneem word na 6 of 12 maande, en vir deel II na 18 maande met mondelinge eksamens in al die vakke en 'n praktiese toets in die twee skoolvakke. Die kandidaat moes slaag in hoër Engels of Nederlands. Die voertaal in die eksamen was Engels of Nederlands (later Afrikaans). Die O.1-kursus is in 1923 opgehef en van 1924 af is 'n nuwe onderwysdiploma ingestel, naamlik die Hoër Onderwysdiploma, aan die P.U.K. aangebied. Dit was 'n eenparige, nagraadse kursus, wat die volgende vakke ingesluit het: Metodiek van 2 skoolvakke, Beginsels en Psigologie in Geskiedenis van die Opvoeding, Gesondheidsleer en Liggaamlike Opvoeding, Praktiese Vakke en werk (onderwys, welsprekendheid, bordwerk, taalwerk in een of albei amptelike tale met een hoër toets verpligtend en 'n laer toets in die ander taal). Dit was ' $n$ interne opleiding. Die leergange is in volle besonderhede gegee vir Beginsels en Metodes van die Onderwys, Skoolbeheer en Tug, Sielkunde en Geskiedenis van die Opvoeding, Praktiese Onderwys op die laer en middelbare skool. Van die begin van 1934 is die huidige U.O.D. en 'n U.L. O.D. aangebied - die diplomas is van tyd tot tyd inhoudelik verander en selfs vermeerder.

\section{Die opleiding vir grade in die Opvoedkunde:}

Soos in die meeste Westerse lande die akademiese studie van die Opvoedkunde verband gehou het met en gegroei het 
uit die kursusse vir die opleiding van onderwysers, so het in ons land die opleiding vir die grade in die Opvoedkunde ontwikkel uit en saam met die opleiding van die diplomas vir die onderwysers.

Aan die P.U.K. is in 1923 vir die eerste maal 'n graad in die Opvoedkunde aangebied. Die eerste kandidaat vir die nuwe graad was die skrywer, en dit was die graad Magister Educationis soos ingestel deur die Universiteit van Suid-Afrika vir sy samestellende Kolleges en vir eksterne studie in sy Senaatsitting van 1923. Die studiekursus vir die M.Ed. het omvat: I. 'n Verpligte tesis oor 'n opvoedkundige tema gelyktydig met of wel na die skriftelike eksamen; II. Drie verpligte vakke en vraestelle: (1) Filosofie van die Opvoeding, (2) Algemene Opvoedkundige Sielkunde, (3) Proefondervindelike Sielkunde en Psigopatologie; III. Twee vakke na keuse uit (1) Geskiedenis van Opvoedkunde in Suid-Afrika en Hedendaagse Probleme in Administrasie, (2) Spesiale studie van Outeurs of Bewegings met spesiale studie van 2 opvoedkundiges (bv. Rousseau en Pestalozzi), en (3) Beginsels van Etiek, Logika of Biologie. Die tweede kandidaat vir die graad was W. J. Snyman (later adjunk-direkteur van Onderwys in Transvaal). Tot 1950 was daar ruim 60 kandidate wat die graad verwerf het.

Die tweede graad wat die P.U.K. aangebied het, was die graad Doctor Philosophiae in die Opvoedkunde. Weer was die skrywer in 1925 die eerste kandidaat wat die graad D.Phil. behaal het. Die voorvereiste was 'n gepaste toelatingsgraad en 'n selfstandige dissertasie wat mondeling verdedig moes word. Die tweede kandidaat was M. J. Prinsloo in 1933. Ruim 50 studente het die doktorsgraad verwerf teen selfstandigwording in 1951. Van 1947 af is die betiteling van die doktorsgraad in die Opvoedkunde genoem Doctor Educationis.

Die derde graad was die Baccalaureus in Opvoedkunde; die B.Ed. van 1947 af om die sg. vraestelle van die M.Ed. te vervang. Die M.Ed. is van toe af net toegeken op 'n verhandeling. Tot 1950 het meer as 120 kandidate die graad B.Ed. verwerf. Gelykwaardig aan die B.Ed. is twee ander opvoedkundige grade ingestel: die B.P.Ed. (vir Liggaamlike Opvoeding) in 1949 en die B.Dom.Ed. (vir Huishoudkundige Opvoeding) in 1951.

Die personeel, die departement en die fakulteit:

Hierin het die eerste Rektor van ons Inrigting weer die 
inisiatief geneem. In 1921 het die Potchefstroomse Normaalkollege in werking getree. Die hoof daarvan was mnr. J. S. van Heerden en 'n senior dosent die skrywer self. Mnre. Van Heerden en Coetzee het van 1921 af as deeltydse dosent ook die werk aan die P.U.K. van die opleiding van onderwysers behartig. In 1922 is die Departement Opvoedkunde onder die Fakulteit van Lettere en Wysbegeerte ingestel met mnr. J. S. van Heerden as die eerste maar deeltydse professor en die skrywer as die deeltydse lektor. In 1925 het die eerste voltydse professor (die skrywer) in die Opvoedkunde aan die P.U.K. begin werk. Die twee professore het toe die werk vir die Opleiding van onderwysers waargeneem en die voltydse professor al die werk vir die opleiding vir die grade. Aan die eerste kandidaat (M.Ed.) in 1923 is hulp gebied deur prof. Van Heerden, F. Postma en J. D. du Toit. By die opleiding van onderwysers het die Normaalkollege ook 'n aandeel gehad, terwyl die P.U.K.-vakprofessore die metodiek van die middelbare-skoolvakke behartig en hulp gebied het in die praktiese vakke.

In 1934 het die Opvoedkunde 'n selfstandige Fakulteit geword met Departemente vir Teoretiese, Empiriese, Historiese en Praktiese Opvoedkunde. 'n Eie dekaan (die skrywer) is toe ook benoem en gekies - die Raad van die P.U.K. het verkies om 'n vaste Dekaan tot 1953 in bevel te stel.

In $1945 \mathrm{kom}$ dr. H. J. J. Bingle as senior lektor (later as professor) veral vir die Departement Empiriese Opvoedkunde en met ' $n$ volle aandeel aan die Departement Praktiese Opvoedkunde. 'n Vyfde Departement is bygevoeg deur die benoeming van 'n senior lektor, nl. dr. D. P. J. Smith, as hoof van die Departement Liggaamlike Opvoeding. Met selfstandigwording in 1951 was daar dus vyf Departemente en minstens drie voltydse dosente. Daarna het die Fakulteit vinnig ontwikkel en tot een van die sterkste Fakulteite in ons land gegroei. Tans is daar 5 voltydse professore: B. C. Schutte, J. J. Snyman, S. J. Preller, A. G. Coetsee, D. P. J. Smith. Die meeste studente selfs in die onderwysersopleiding is gegradueerd, en alle studente vir die verskillende grade is vanselfsprekend reeds gegradueerd.

Ek wil die oorsig afsluit deur kortliks op 'n paar sake te wys. Soos die verhaal hierbo aantoon, het die Gereformeerde Kerk van sy ontstaan af intens belang gestel in die skool en in die onderwyser as plaasvervangende ouer. In die Kerkorde van die kerk staan dan ook een belangrike artikel (21) waarin ons lees: Die kerkrade moet orals toesien dat daar goeie onder- 
wysers is. Hierdie toesig vereis eerstens die regte opleiding van onderwysers vir die Gereformeerde skool. Die Algemene Sinodale Vergadering van die Gereformeerde Kerk het deurgaans aandag aan die skool en die onderwyser gegee. Die Teologiese Skool van die Gereformeerde Kerk het opdrag van die Sinode van 1869 om aandag te gee ook aan die opleiding van onderwysers; en die Sinode van 1875 het die aanstelling deur die Kuratore van 'n professor in die Lettere goedgekeur. In 1879 is die eerste drie onderwysers afgelewer en in 1894 keur die Sinode 'n skema vir 'n onderwyserseksamen goed. En so gaan dit aan.

Die kerk het die mense voorsien ook vir die opleiding van onderwysers in die persone van die literariese professore $P$. Postma (1877), M. Postma (1880), S. Postma (1890), J. A. du Plessis (1896), P. C. Snyman (1898), D. Postma M.sn. (1904) en veral F. Postma M.sn. (1904) - hulle het almal aandag aan die opleiding gegee. Maar ook die teologiese professore self $\mathbf{D}$. Postma (1877), J. Lion Cachet (1892), J. D. du Toit (1911), S. O. Los (1914), J. A. du Plessis (1920), C. J. H. de Wet (1925), P. J. S. de Klerk (1949) en B. J. de Klerk (1952) het hulle nooit onbetuigd gelaat nie, so ook neem die huidige professore S. du Toit (1935), W. J. Snyman (1946), J. P. Jooste (1946), S. P. van der Walt (1953), H. du Plessis (1959) en S. J. van der Walt (1961) 'n aktiewe aandeel in die skoolstryd.

Dit is veral die eerste Rektor (prof. F. Postma) van die nuwe Universiteitskollege wat 'n wesentlike verandering in die opleiding van onderwysers gebring het: in 1920 met die Unie 0.1 en 'n deeltydse dosent, in 1922 met die aanstelling van 'n deeltydse professor in die Opvoedkunde en in 1925 van die van 'n voltydse professor, in 1922 met die instelling van 'n Departement Opvoedkunde en in 1934 met die van die huidige Fakulteit Opvoedkunde. Van 1925 af egter neem die voltydse professor(e) die taak van die opleiding van onderwysers op eie verantwoordelikheid, as ook die van die opleiding van studente vir die grade in die Opvoedkunde. Die vaste personeel van die Fakulteit Opvoedkunde het op die terreine van die Teoretiese, Empiriese, Historiese, Praktiese en Liggaamlike Opvoedkunde grondliggende werk van blywende waarde vir die Christelike Opvoedkunde gelewer - in artikels, brosjures, boeke, tydskrifte en ook in die gesproke woord op menige liggaam, in konferensies en kongresse, in studiekringe, in kerklike deputaatskappe. 
Die aandag moet ook gevestig word op die hoogstaande wetenskaplike bydraes in proefskrifte en verhandelinge van die doktore en meesters in die Opvoedkunde. Hul bydraes lê op al vyf genoemde terreine van die Opvoedkunde. Ook die baccalaurei en die onderwysers dra hul onmisbare deel by tot die uitbouing van die Opvoedkunde. En nie minder nodig is dit om te wys op die verantwoordelike plekke in die samelewing ingeneem deur die studente van die Fakulteit Opvoedkunde aan ons Universiteit (en sy voorgangers). Onder hulle is daar predikante, universitêre rektore, professore en lektore, rektore en dosente van Onderwyskolleges, direkteurs en inspekteurs van die openbare onderwys, parlementslede en selfs ministers in die kabinet, skoolhoofde (laer en middelbare) en rigtinggewende manne en vroue in die laer en middelbare skool.

Maar - en daarmee sluit ek af - die hoogste bydrae van die beoefenaars en studente van die Opvoedkunde aan ons Inrigting (Literariese Departement, Universiteitskollege, Universiteit) is die vestiging van 'n Christelike Opvoedkunde op Calvinistiese grondslag tot eer van onse God en tot diens van ons medemens, ons land en volk.

Ook hier gee ons aan God alleen die eer en die dank: Hy het ons gebruik in sy diens!

Pretoria.

J. Chr. Coetzee. 